DOI: 10.21892/978-958-5547-64-3.6

\title{
6. La frontera de lo punible del derecho de autor en el entorno digital: un nuevo reto para la justicia
}

Alejandra González Villarreal ${ }^{1}$

\section{Introducción}

A medida que una sociedad evoluciona se presentan avances económicos, políticos y, por supuesto, tecnológicos. Estos últimos implican potenciales beneficios respecto del conocimiento, de la creatividad, en suma, de la innovación. El derecho, como instrumento de organización social que regula las conductas de las personas con miras a preservar el orden y la unidad, debería brindar una respuesta acorde con estos avances; sin embargo, es notable como la tecnología, aun mas las nuevas tecnologías, han estado al servicio de la sociedad, más de lo que el derecho ha dado alcance con su regulación a los escenarios en los que están inmersas las nuevas tecnologías.

Debido a ese poco alcance normativo, los efectos de la tecnología muestran otros resultados adversos al fin social, que en verdad esta persigue, y, por supuesto, el abordaje de las normas existentes deja de ajustarse a la realidad actual. En el ordenamiento jurídico el desarrollo del ejercicio del derecho está basado, en gran parte, en la aplicación de normas preexistentes. No es menos cierto que si la dinámica fuera otra, se verían afectados potencialmente derechos, principios, valores y preceptos fundamentales de nuestro actual Estado social y democrático de derecho, sin mencionar la alteración de situaciones jurídicas ya establecidas, y a cuyos problemas se han encontrado soluciones armónicas.

Sin embargo, hay una gran diferencia entre alterar la regla de la aplicación de normas preexistentes y recurrir no simplemente a transformaciones sino sobre todo a evoluciones para que con el desarrollo necesario del ordenamiento jurídico se de alcance a los nuevos escenarios

1 Estudiante de Derecho de la Universidad Tecnológica de Bolívar. 
de la sociedad. Ello, explicado desde la teoría del pre- compromiso de Stephen Holmes, quiere decir que las generaciones actuales no tienen la obligación de someterse a normas pactadas por generaciones anteriores que no correspondan a dos elementos claves como son las necesidades y las expectativas.

Ahora bien, lo anterior no es un planteamiento reciente, sino la consecuencia lógica del progreso. Pues, desde las primeras civilizaciones hasta la organización de la sociedad en Estados, se han requerido innovaciones a fin de satisfacer los retos que surgen (Christian, 2005). La tecnología, como todo aquel proceso o procedimiento de optimización que ayuda a generar desarrollo, es una respuesta clara a dichas necesidades, que se vio reflejada desde el mejoramiento de técnicas agrícolas hasta la invención de máquinas para la producción industrial en masa.

No obstante, a medida que las personas tienen nuevas necesidades, aparecen también nuevas formas de responder a ellas. Ejemplo de esto son las tecnologías de la información y la comunicación, equivalentes a la aparición de la televisión, la radio, el teléfono, los TCP/IP o Internet Protocol, el correo electrónico, el sistema operativo Windows, los dispositivos de GPS, los servicios de mensajería instantánea, las comunidades virtuales como YouTube, Facebook, etc.

Y así como la tecnología ha estado al servicio de la sociedad, también lo ha estado al servicio del derecho, como se puede apreciar de la informática jurídica, que consiste en la aplicación de la tecnología como instrumento del derecho. Por otro lado, si no hablamos de informática jurídica sino de derecho informático, nos estamos refiriendo a una rama autónoma del derecho que tiene por objeto desarrollar normas que regulen la tecnología. Así, respecto a esta diferenciación, bien se puede decir que no es igual la respuesta que ha dado la tecnología frente a las necesidades y expectativas de la sociedad, que la brindada por el derecho frente a la regulación de las nuevas tecnologías.

Es por ello que se presentan tensiones entre los derechos de unas personas y las acciones de otras, de cara a aquello que les es protegido -o limitado-y permitido -o exigido- en la relación de derecho y tecnología. Un claro ejemplo en la actualidad es el derecho de autor en el entorno digital. 
Sin embargo, para abordar mejor esta problemática, primero abrámonos paso en el mundo del derecho de autor.

Con el fin de abordar la problemática anteriormente descrita, el presente texto lleva a cabo un ejercicio reflexivo -desde un marco normativo, jurisprudencial y doctrinal- al analizar las implicaciones de la escasa regulación de los derechos patrimoniales de autor en el entorno digital. Por lo tanto, lo que se busca en este capítulo de libro es denotar que la seguridad jurídica va de la mano de las expectativas y necesidades que nuestra sociedad de la información le demanda al derecho en pro de una verdadera justicia material.

\section{Sobre el régimen de derecho de autor}

De acuerdo con autores como L'Hoeste (2016) la propiedad intelectual es una forma de propiedad que se ejerce sobre las creaciones del intelecto, producto del talento humano, y que son plasmados en bienes de carácter material o inmaterial. Sin embargo, esta noción deja por fuera otros activos intangibles, como las invenciones, pues, pese a que su concepto pueda confundirse con el de una creación, no son iguales, así como se observará más adelante.

Una definición más amplia indica que la propiedad intelectual es una disciplina jurídica que abarca la protección de todas las formas de manifestación de la actividad creativa, inventiva y distintiva del ser humano, generando un derecho de apropiación y de exclusividad en un ámbito temporal y geográfico, en favor de innovadores e inversores. (VargasChaves, 2017).

Estas formas de manifestación, también denominadas 'activos de propiedad intelectual', son bienes inmateriales en tanto que, perteneciendo al patrimonio de la persona de la cual se predica el derecho de apropiación y exclusividad, son susceptibles de valorarse económicamente.

La propiedad intelectual se divide en dos grandes sistemas. Por un lado, los derechos de autor y derechos conexos que protegen las obras audiovisuales, literarias, estéticas y científicas, las interpretaciones, 
traducciones, obras de dibujo, escritos e ilustraciones, extendiendo la protección a los artistas, intérpretes y ejecutantes.

Por otro lado, está la propiedad industrial que se divide en dos subsistemas: las nuevas creaciones que abarcan las invenciones, los modelos de utilidad, los diseños industriales, los circuitos integrados y el secreto empresarial; $y$ los signos distintivos que incluyen las marcas, las indicaciones geográficas -dentro de las cuales se encuentran las indicaciones geográficas propiamente dichas, y las denominaciones de origen-y, por último, los nombres de dominio.

Para fines de este texto, se profundizará acerca del régimen de derechos de autor y derechos conexos. Este es el conjunto de normas que protegen todas aquellas creaciones científicas, artísticas y literarias que no tienen aplicación industrial, y son el fruto del ingenio y la creatividad del hombre, en tanto sean perceptibles por los sentidos en cualquier soporte tangible o intangible y, además, sean originales.

Un error en el que se suele incurrir es considerar que los derechos de autor protegen las ideas. Estas son libres, íntimas y producto del ingenio de las personas, pero la protección del régimen de derechos de autor va más allá, pues se centra en la creación que realizan los autores al materializar o plasmar esas ideas en un soporte tangible o intangible, cuyo resultado es una obra artística, científica o literaria en cualquiera de sus formas (Centro Colombiano de Derechos de Autor, 2002). De acuerdo con el artículo 8 de la Ley 23 de 1982, se establece la categorización de las obras en individuales, en colaboración, colectivas, anónimas, seudónimas, inéditas, póstumas, originarias y derivadas.

Con todo, pese a que no se protegen las ideas sino la materialización de las mismas en un soporte determinado, para la protección de esa creación no se exige formalidad alguna, es decir, así como se observa en el artículo $9^{\circ}$ de la Ley 23 de 1983, las obras están protegidas desde el momento mismo de su creación, por tanto, no requieren de ningún registro. Sin embargo, el registro que se tramita ante la Dirección Nacional de Derecho de Autor U.A.E. está concebido para brindar mayor seguridad jurídica y publicidad a los titulares, permitiendo la oposición ante terceros. En síntesis, la realización del registro es meramente declarativo, y no constitutivo de la protección. 
De acuerdo con el artículo $4^{\circ}$ de la ley 23 de 1982, son titulares de estos derechos: (a) El autor de su obra; (b) El artista, intérprete o ejecutante, sobre su interpretación o ejecución; (c) El productor, sobre su fonograma; (d) El organismo de radiodifusión sobre su emisión; (e) Los causahabientes, a título singular o universal, de los titulares; (f) La persona natural o jurídica que, en virtud de contrato, obtenga por su cuenta y riesgo la producción de una obra científica, literaria o artística realizada por uno o varios autores en las condiciones previstas en el artículo 20 de esta Ley.

De igual forma, el artículo $3^{\circ}$ de la misma Ley expresa que los derechos de autor comprenden para sus titulares las facultades exclusivas siguientes:

A. De disponer de su obra a título gratuito u oneroso bajo las condiciones lícitas que su libre criterio les dicte.

B. De aprovecharla, con o sin fines de lucro, por medio de la imprenta, grabado, copias, molde, fonograma, fotografía, película cinematografía, videograma, y por la ejecución, recitación, representación, traducción, adaptación, exhibición, transmisión, o cualquier otro medio de reproducción, multiplicación, o difusión conocido o por conocer.

C. De ejercer las prerrogativas, aseguradas por esta Ley, en defensa de su "derecho moral", como se estipula en el Capítulo II, Sección Segunda, artículo 30 de esta Ley. Adiciona mediante la Ley 44 de 1993.

Los derechos morales o personalísimos que el autor tiene sobre su obra se caracterizan por ser inalienables, imprescriptibles e inembargables, y le permiten, bajo su derecho moral de paternidad, exigir la indicación de su nombre o seudónimo en la obra toda vez esta sea reproducida, transformada, distribuida o comunicada al público.

Así mismo, el autor tiene un derecho moral de integridad que le permite evitar que se realicen deformaciones, mutilaciones, cambios u otras modificaciones a la obra, cuando con tales conductas se pueda causar, o se cause, un perjuicio que atente contra su buen nombre, su reputación o con la naturaleza de la obra. 
Estos derechos no podrán ser cedidos ni transmitidos por el autor, es decir, no puede renunciar a ellos y no tienen límite de tiempo para su protección, por lo que en vida los ejerce el autor, y a su fallecimiento sus herederos y a falta de estos, se encarga el Estado (Ley 23 de 1982).

Por otra parte, los derechos patrimoniales son aquellos que le permiten al autor disponer libremente de su obra para obtener un provecho económico. Por tanto, puede enajenar, ceder o transar su propiedad a cualquier título o también renunciar a ella.

De acuerdo con Ríos (2011), los derechos patrimoniales se dividen en cuatro grandes grupos. El primero, denominado derecho de reproducción, incluye la edición y cualquier forma de fijación, bien sea magnética, audiovisual o en fonograma. El segundo, denominado derecho de comunicación pública, incluye, entre otros, la transmisión por satélite, Internet, cable, radio, fibra óptica, la representación, exposición pública o exhibición. El tercero, conocido como el derecho de transformación, le permite al autor alterar su obra mediante traducción, adaptación o llevándola de un género a otro. Y por último, el derecho de distribución, que se manifiesta en derechos como el de alquiler, préstamo público e importación.

De acuerdo con la Ley 23/82, estos derechos le corresponden al autor y se protegen durante su vida y hasta ochenta años más después de su muerte. Ello, si el autor no transfiere sus derechos, pero en caso de que los transfiera, solo se protegerán por setenta años, contados a partir de la transferencia.

\section{El entorno digital y los retos del derecho de autor como bien jurídico en el ámbito penal}

Con cada nueva etapa, con cada nueva necesidad, avanza la tecnología. Uno de los efectos más importantes de ese avance es el acceso a la información y a los medios de comunicación más óptimos. Anteriormente, se usaban cámaras con un rollo fotográfico; se calculaba la hora con las manecillas del reloj; la imagen en el televisor era distorsionada o borrosa; se pasaba de una canción a otra por medio de los botones de un VHS o bien se reproducían videos a través de Betamax. 
Actualmente pueden observarse las imágenes tomadas directamente desde el lente de la cámara; la hora se observa en números en la pantalla de un reloj o de cualquier otro dispositivo electrónico como teléfonos móviles o computadoras; las imágenes en un televisor se ven en alta definición; se pueden alterar de forma táctil los números representativos de las variaciones del volumen en un equipo de sonido o, más bien, cada vez menos la música se reproduce a través de dispositivos que no sean un teléfono móvil, un IPod o un computador; y, por supuesto, con plataformas como Netflix, Google Play o Amazon Prime, rara vez necesitamos de un DVD.

Los avances a los que aquí se refiere hacen alusión al proceso por el que ha pasado la tecnología de la información y la comunicación, denominado digitalización, por medio del cual la información que antes era análoga se traduce en códigos binarios, es decir, todo se reduce a dos dígitos; de ahí el nombre 'digital'.

Ahora bien, si con estas nuevas tecnologías se ha logrado facilitar procesos y actividades que aportan mejoras en las dinámicas sociales de las personas, ciertamente no es lo único que se ha facilitado o fortalecido. Hay que resaltar que con el acceso a estos dispositivos de información y comunicación digital y provistos de las ventajas de sus características, como la inmediatez de la comunicación a distancia, la posibilidad de la realización de acciones masivas y el anonimato- los agentes del delito han encontrado en la tecnología un aliado, toda vez que esta les simplifica el desarrollo de la ejecución de sus conductas. En definitiva, la tecnología ha resultado un potenciador del delito. (Temperini, 2014).

Lo anterior se observa reflejado en dos clases de conductas bien específicas. La primera atenta contra bienes jurídicos que tradicionalmente se han considerado punibles por el derecho penal y se han tipificado en el Código Penal colombiano, tales como la estafa, la extorsión, las amenazas, etc.; pero con la particularidad de que se cometen a través de medios electrónicos. La segunda conducta consiste en que la acción delictiva no recae sobre cualquier bien jurídico, sino especialmente sobre el bien jurídico de la información y los datos personales. Estas conductas corresponden respectivamente a los delitos electrónicos y a los delitos informáticos.

Los delitos informáticos derivan su origen de la Ley 1273 de 2009, "por medio de la cual se modifica el Código Penal para crear un nuevo bien 
jurídico tutelado -denominado de la protección de la información y de los datos- y se preservan integralmente los sistemas que utilicen las tecnologías de la información y las comunicaciones, entre otras disposiciones." Este bien jurídico acoge los tres pilares de la información que se buscan resguardar: la confidencialidad, la integridad y la disponibilidad.

Sin duda, para ofrecer la configuración de la protección de estas características de la información, el Código Penal se apropia de lo expresado previamente por la Ley 527 de 1999. En consecuencia, de sus artículos 11 y 12, y además del análisis que concibe Flórez (2014) de los mismos, se infiere que, en primer lugar, la integridad implica que el contenido de la información sea inalterado; en segundo lugar, que la disponibilidad está referida a la capacidad de la información de estar siempre accesible para ser procesada por las personas autorizadas y, por último, que la confidencialidad alude a la necesidad de que la información solo sea conocida por esas personas autorizadas.

Ahora bien, además del hecho de que la tecnología resulta ser un potenciador para los delitos, en especial para los delitos informáticos, estos tienen otros problemas relacionados con la falta de cooperación internacional, por ejemplo, la falta de acuerdos globales acerca de qué tipo de conductas deben constituir estos delitos; ausencia de acuerdos globales en la definición legal de dichas conductas delictivas; falta de especialización de la policía, fiscales y funcionarios judiciales en el ámbito de estos delitos; falta de armonización entre las diferentes leyes procesales nacionales referentes a su investigación; carácter transnacional de múltiples delitos cometidos mediante el uso de computadoras (lo que significa que el agente del delito no necesita estar en el mismo lugar en donde lo cometió); ausencia de tratados de extradición, de acuerdos de ayuda mutuos y de mecanismos sincronizados que permitan la puesta en vigor de la cooperación internacional.

Por otro lado, ya en el ámbito del derecho de autor, el Código Penal tipifica en tres artículos subsiguientes otras conductas relativas a la violación de los derechos de autor, denominadas de la siguiente forma: violación a los derechos morales de autor (Artículo 270), violación a los derechos patrimoniales de autor y derechos conexos (Artículo 271), y violación a los mecanismos de protección de derecho de autor y derechos conexos y otras defraudaciones (Artículo 272). 
Respecto al artículo 271, la única referencia que el Código plantea para las ocasiones en que se considera punible que la reproducción de las obras se haga por medios informáticos, es un parágrafo adicionado por el artículo 36 de la Ley 1915 de 2018, que resalta el elemento subjetivo, como es la intencionalidad del agente tendiente a obtener un beneficio económico directo o indirecto, y a llevar su ejecución a una escala comercial. Quedando entonces relegada al abordaje de un único apartado, la complejidad de las situaciones que se presentan en la relación 'derechos patrimoniales de autor versus nuevas tecnologías'.

Esta preocupación particular por la tensión entre nuevas tecnologías y derechos patrimoniales de autor, y no entre nuevas tecnologías y derechos morales de autor, se explica claramente en palabras de Carbajo (2002):

(...) con la digitalización los interés económicos de los autores y de la industria de contenidos prevalecen sobre los intereses personales de los autores, con lo que un reforzamiento de las facultades morales podría retrasar el desarrollo de la industria multimedia y de la explotación en línea de obras, haciendo peligrar, en definitiva, la evolución cualitativa de la sociedad de la información.

Dado lo anterior, es ilógico que las consecuencias de los supuestos de hecho relativos a la violación de los derechos que primordialmente se dejen a la aproximación de un parágrafo con el que se busca proteger a los titulares, como son los derechos patrimoniales de autor en el marco de la incertidumbre que traen las nuevas tecnologías,

Ello, en último caso, genera una incertidumbre jurídica, pues si bien es posible pensar, a pesar de lo anterior, que la mayoría de los casos se resuelvan teniendo en cuenta esta salvedad de la norma, porque, por ejemplo, la discrecionalidad de un juez se haya basado en un método de interpretación sistemático o finalista, y por ello haya puesto en consideración la realidad actual para proferir su decisión. Igualmente puede darse que un juez, en virtud de un método de interpretación histórico, decida indagar por la intención original que tuvo el legislador al redactar esa norma, es decir, la relativa a la violación a los derechos patrimoniales de autor, y en consecuencia se pregunte ¿Qué habrá querido expresar el legislador con "beneficios económicos directos o indirectos"? o ¿Qué habrá querido 
expresar con que las reproducciones de la obra se hagan a escala comercial? ¿Quizá esto último lo podrá relacionar con la magnitud de los perjuicios económicos que se generen para el titular del derecho?

Lo anterior se explica de mejor forma en razón de los diversos temperamentos interpretativos a los que se refieren Parra \& Lagunas (2018). Estos autores sostienen que toda idea, creencia o filosofía, tiene su origen en el temperamento de cada persona, y que lo mismo sucede con los abogados y la interpretación, puesto que las estrategias y herramientas de interpretación que se aplican en el derecho también pueden entenderse como una extensión de los temperamentos de los abogados, y al existir divergencia temperamental, se emplean entonces criterios y herramientas diversas.

Ahora bien, con ello no se pretende expresar una oposición a la actividad de interpretación propia de la rama judicial o hasta la de creación que algunas veces debe realizar. Y es que, así como a falta de precisión o claridad en un área del derecho, debe acudirse a otra para trasladar, interpretar o aplicar normas, lo mismo pasa con las ramas del poder público, pues cuando en una se observan deficiencias, no se debe impedir que, de manera proporcional, parte de sus funciones se remitan a otra. Como sucede constantemente con la legislativa por la falta de exactitud, claridad o incluso regulación, y con la judicial (de forma especial con los jueces constitucionales) que se ve en el papel de crear nuevos principios, reglas e inclusive derechos o restricciones.

No obstante, la labor de interpretación de un juez penal es mucho más restrictiva que la de un juez constitucional, justamente por el carácter excluyente de las normas imperativas, que implica que deben estar desprovistas de la textura abierta del lenguaje de la que habla Hart (1980). Lo cual no quiere decir que, dado que este tipo de normas deban ser excluyentes y precisas, su abordaje y regulación no pueda extenderse. Lo que realmente significa es que con ellas debe dejarse el mínimo rango de interpretación posible. Y aun así, se observa cómo el escaso desarrollo normativo en la materia exhorta al juez a buscar soluciones a esos problemas de interpretación.

Así que, en efecto, por un lado, surgen nuevas amenazas porque la tecnología avanza, ante lo cual se tienen pocas soluciones. Por otro lado, 
persiste la posibilidad de que lo preocupante no sean las amenazas a los derechos de autor, sino la desproporcionalidad de la consecuencia jurídica impuesta a una persona porque la norma no es precisa ni su abordaje suficiente, en comparación con los conflictos referentes al derecho de autor y las nuevas tecnologías.

Pese a ello, no se puede expedir una nueva ley cada vez que se den avances tecnológicos, y en consecuencia se disponen de tipos penales muy amplios para cobijar todos los supuestos de conductas. El problema consiste en que, por esa misma amplitud, y especialmente en el caso del derecho de autor, los tipos terminan abarcando casos en donde el "agente" no incurre en ninguna acción u omisión, o bien no tiene una intención, que sea equivalente a realizar conductas que la sociedad considere reprochables, pero aun así está bajo la posibilidad de ser judicializado porque su conducta se ajusta a la configuración del tipo penal.

Visto de esta forma, nos encontramos ante dos posibilidades: (i) Se pueden replantear las normas relativas a las infracciones del derecho de autor en el marco de la era digital, restringiendo su indeterminación y ampliando su abordaje; o (ii) Seguimos sometidos a un contexto de incertidumbre, ateniéndonos a la indeterminación de las normas y a la discrecionalidad de los jueces.

Cabe anotar que se alude al concepto de 'conductas reprochables' en razón del artículo 12 del Código Penal, el cual estipula que "Sólo se podrá imponer penas por conductas realizadas con culpabilidad." Esto quiere decir que para que se pueda imponer una pena a una determinada conducta, esta no solo debe ser típica, o no solo típica y antijurídica. Debe ser típica, pero también antijurídica y culpable; lo que lleva a preguntarse entonces, ya que el artículo no lo define: ¿Qué se considera por culpabilidad?

De acuerdo con la sentencia del 9 de agosto de 1983 de la Corte Suprema de Justicia - Sala Penal, se entiende por culpabilidad "la actitud consciente de la voluntad que da lugar a un juicio negativo de reproche, porque el sujeto actúa antijurídicamente pudiendo y debiendo actuar de otra manera, y que en nuestro derecho positivo puede adoptar la forma del dolo, de la culpa o de la preteritención (...)"

Conforme a lo anterior, como solo se pueden imponer penas sobre conductas cometidas con culpabilidad, es decir, sobre conductas que den 
lugar a un juicio negativo de reproche, se entiende entonces que bajo ningún contexto se consideraría justo imponer penas sobre conductas que no se consideren reprochables.

Sin embargo, veremos a continuación cómo en este contexto de tensión entre nuevas tecnologías y derechos de autor y la falta de regulación en la materia, cabe la posibilidad de imputar consecuencias jurídicas a una persona que no incurre en conductas reprochables, solo porque con el abordaje de la norma no se ha dejado claro cuáles son los límites razonables en la protección de los derechos patrimoniales de autor frente a las nuevas tecnologías.

\section{El caso de Diego Gómez, cuando compartir no es delito}

Diego Gómez es un biólogo egresado de la universidad del Quindío, inclinado por la investigación relacionada con la conservación de la biodiversidad, específicamente de especies como anfibios y reptiles. Sin embargo, para lograr investigar como estudiante de pregrado, debía recurrir a alternativas a la información brindada por su universidad, dado que esta no contaba con los recursos para proporcionar el acceso a importantes bases de datos bibliográficas. Lo cual, desde su perspectiva, limitaba el acceso al conocimiento tanto de estudiantes como de docentes.

Pese a que Internet había resultado un aliado en el proceso de búsqueda y estudio: la dificultad más palpable era no poder acceder a investigaciones desarrolladas en Colombia con información básica para hacer conservación. En palabras de Diego Gómez: "para conservar hay que conocer qué conservar, y lo que se quiere conservar se identifica con las investigaciones previas." (Gómez, 2017).

Así pues, en el año 2011, Diego Gómez decidido a continuar adelante con su trabajo de investigación y motivado por la intención de que todos pudiesen tener acceso al conocimiento, compartió en Internet una tesis de maestría mediante la cual podía identificar a los anfibios que él encontraba en sus trabajos de campo. Esta acción implicó que el autor de la tesis, Andrés Acosta Galvis, presentara una denuncia en su contra por violación a los derechos patrimoniales de autor y derechos conexos, argumentando que la conducta había afectado la normal explotación de la obra, dado 
que la finalidad de su trabajo siempre se había llevado a cabo a través de publicaciones de fragmentos de su tesis, es decir, mediante un proceso de sometimiento, y en vez de ello, a partir de su reproducción total, la información de su trabajo podría ser utilizada por quien la obtuviera.

Sin embargo, peritos como Daniel Torres Farkonert lograron demostrar que la obra ya se encontraba en otros sitios en Internet con anterioridad a la publicación de Diego Gómez, por ejemplo, en un grupo grupo cerrado de Facebook en el que años atrás un integrante solicitó la tesis de maestría del denunciante, y otra persona se la proporcionó por ese mismo medio. Ello descartó la posibilidad de que la conducta de Diego Gómez pudiese afectar la normal explotación de la obra.

En relación con la intención de la conducta, Andrés Acosta afirmó en sus declaraciones que al percatarse que su obra estaba en el sitio web 'es.scribd.com', el costo por descargarla eran 5 dólares, pero nuevamente los investigadores del proceso demostraron que al momento en que Diego Gómez hizo la publicación existía otra forma de descargar el documento. Esto es, subir uno a cambio de ese. Por lo cual, se consideró que habían más elementos que demostraban los fines netamente académicos, que los que demostraban el ánimo de lucro.

El 21 de noviembre de 2017, el Tribunal Superior del Distrito Judicial de Bogotá absolvió a Diego Gómez de los cargos imputados por el delito de violación de los derechos patrimoniales de autor y derechos conexos, decisión que confirmó el fallo en primera instancia del Juzgado Cuarenta y Nueve Penal del Circuito de Bogotá, que igualmente dictó sentencia absolutoria el 24 de mayo de 2017.

Ahora bien, pese al resultado, Diego Gómez atravesó durante más de cuatro años un proceso penal que de haber terminado con un fallo desfavorable, le hubiese implicado una pena de 4 a 8 años en prisión. Todo porque no contempló cuáles eran los límites razonables de la regulación del derecho de autor, sin que pudiese haber un delito por compartir conocimiento a través de medios digitales, y sin ánimo de lucro, con la intención de promover su acceso abierto para fines académicos.

Como ya se mencionó, la sentencia del Tribunal Superior del Distrito Judicial de Bogotá, que confirmó el fallo absolutorio, fue proferida el 21 de noviembre de 2017. La norma relativa a la violación de derechos 
patrimoniales de autor a través de medios informáticos, de la que se hizo referencia anteriormente, se adiciona al Código Penal por el artículo 36 de la Ley 1915 de 2018. Lo que quiere decir, en primer lugar, que los jueces que emitieron una decisión sobre el caso de Diego Gómez no pudieron tener en cuenta el contenido del parágrafo que actualmente pertenece al artículo 271 del Código Penal, porque aún la Ley que lo contenía no había entrado en vigencia.

Lo que permite concluir que la labor del juez en este caso, a pesar de la falta de normatividad nacional al respecto, permite que los conflictos resultantes de la relación entre la regulación de derechos de autor y nuevas tecnologías, se resuelvan teniendo en cuenta: (i) La realidad actual de la sociedad, (ii) El elemento subjetivo referido a la intencionalidad con que se realiza una determinada conducta; y (iii) Las excepciones y limitaciones del derecho de autor, sí pueden aplicarse al caso correspondiente.

En segundo lugar, cabe aclarar que esto también quiere decir que solo hasta la Ley 1915 de 2018, se incluyó en la legislación nacional la regulación de la violación de los derechos patrimoniales de autor por medios informáticos, a pesar de que la relación entre propiedad intelectual y nuevas tecnologías, ya dejaba sus consecuencias desde tiempo atrás.

Según Carbajo (2002): "El rápido desarrollo de las tecnologías de la información -consecuencia de la convergencia entre la informática, la tecnología digital desarrollada por la microelectrónica y las telecomunicaciones- ha traído consigo importantes modificaciones en las relaciones sociales, económicas y culturales que se manifiestan con especial intensidad en el campo de la industria relacionada de alguna manera con el mundo de la cultura, el entretenimiento y la información (...)"

De acuerdo con lo anterior, si bien es cierto que la tecnología seguirá avanzando, también lo es que el derecho no ha tenido hasta ahora la suficiente capacidad para abordar esos cambios. De continuar así ¿Cuánto se deberá esperar para que vuelva a incluirse únicamente otro parágrafo en el Código Penal, si se percata en una nueva ocasión, que las dinámicas de la sociedad y del mundo digital necesitan abordarse con una regulación ajustada a la actualidad?

Con todo esto, persiste la inquietud de por qué sería preferible esperar a que los jueces lleguen a este tipo de decisiones, aun con un contenido 
normativo insuficiente, en vez de reformar el marco legal para ampliar la regulación de la materia y hacer más precisa la redacción de la norma, obteniendo por tanto una limitación al margen de interpretación, y con ello mayor seguridad jurídica.

Para el año 2017, estuvo en discusión en el Congreso el proyecto de Ley 146-2017 del Senado, que si hubiese prosperado habría reformado el marco legal del derecho de autor. Este parecía ser la respuesta a los problemas planteados anteriormente. Sin embargo, más allá de proponer soluciones armónicas, el proyecto de ley pretendía imponer más restricciones a los usuarios de Internet respecto de los contenidos que pudiesen publicar, ya que en caso de que se considerara que un contenido estuviese vulnerando algún derecho o política, a los intermediarios o prestadores de servicios de Internet se les habría extendido la responsabilidad si no censuraban dicha publicación.

Todo ello lo que pretendía era ejercer más control sobre los usuarios, haciendo más restrictivo e impositivo el régimen de protección de los derechos de autor en Internet, ya que quien hiciera la publicación no tendría la posibilidad de objetar al respecto si consideraba que su contenido no afectaba ninguna política de los prestadores de servicios o vulneraba los derechos de autor.

Aun así, se espera que los intentos por transformar o actualizar el régimen de protección de los derechos de autor, no se base en intereses privados o decisiones políticas arbitrarias, sino más bien que responda a una regulación en donde la norma tenga en cuenta los usos justos y las dinámicas del mundo digital.

\section{A manera de reflexión final}

Algo que resulta curioso en medio del análisis realizado anteriormente es que tanto Diego Gómez como Temperini (2018) hayan utilizado la palabra "aliado" para referirse a la tecnología. Diego Gómez usó este término para expresar el apoyo que Internet había significado en su trabajo de investigador, porque a través de ella pudo acceder al conocimiento que no podía obtener en su universidad. Por su parte, Temperini lo hizo para afirmar que los delincuentes encontraban en la tecnología un potenciador. 
La razón de ello es la característica de neutralidad que este último autor le otorga a la tecnología.

Como consecuencia de lo anterior, al menos ya son dos las razones que conozcamos, por las que el derecho debe dar alcance a los escenarios que generan las nuevas tecnologías. La primera se da para evitar que continúen tomándose medidas desproporcionadas contra personas que no incurren en conductas reprochables, pero que aun así deben someterse a un proceso penal, solo porque la norma no brinda un abordaje suficiente o es indeterminada. La segunda razón es la que está para impedir que los problemas derivados de la falta de armonización de leyes nacionales e internacionales relacionadas con los delitos informáticos se escapen de la regulación del derecho.

En conclusión, el derecho debe dar alcance a las nuevas situaciones suscitadas por la tecnología, no porque la normatividad deba satisfacer todos sus avances -no se trata de permitir que decisiones arbitrarias respalden un desarrollo que traiga efectos adversos para la sociedad ni pretender que el derecho sea permisivo- más bien, se busca minimizar los riesgos que puedan sufrir las personas porque el derecho no ha logrado armonizarse con las nuevas tecnologías. También para evitar que el desarrollo de la tecnología se escape de la regulación del derecho, ocasionando que se pierda su función o rol como es la de estar al servicio de los intereses de la sociedad.

No obstante, si ya se han establecido las razones por las que el derecho debe dar alcance a estos nuevos escenarios, cabe entonces preguntar ¿Cómo sería posible esto? Teniendo en cuenta que el desarrollo aquí propuesto no es desmedido ni arbitrario. Más bien debe estar determinado por límites tendientes a permitir que en las situaciones jurídicas derivadas de este prevalezcan los fines de justicia, seguridad jurídica y orden público, a los cuales apunta el derecho. 
Por lo anterior, hay que subrayar que del apartado introductorio de este texto puede hacerse dos deducciones sobre la diferencia que existe entre alterar la regla de la aplicación de normas preexistentes y el desarrollo que debe lograr el derecho para dar alcance a los nuevos escenarios que surgen en la sociedad.

La primera de estas deducciones consiste en que es posible lograr que el derecho alcance esos nuevos escenarios con que lo reta la tecnología, sin necesidad de derogar normas o crearlas, solo y exclusivamente para juzgar a una persona. Claros ejemplos de esto se encuentran en la ampliación o modificación parcial de las leyes, las leyes interpretativas o también las decisiones judiciales, que establecen situaciones jurídicas distintas a las ya creadas sin que las normas previas dejen de surtir efecto.

La segunda deducción es relativa a la teoría del pre compromiso, puesto que si las generaciones actuales no deben someterse a normas pactadas por generaciones anteriores que no correspondan a sus necesidades y expectativas (Vargas-Chaves \& Alzate, 2018), entonces, puede tener cabida lo planteado anteriormente. Sin embargo, también es posible que no solo se necesite ampliar o precisar una norma o buscar una situación alterna, sino que se deba prescindir de ella porque atente contra situaciones jurídicas actuales que, no siendo reprochables sino benéficas, deban preservar o empezar a crear efectos en el mundo jurídico.

Para el caso de estudio del presente trabajo, por supuesto, aplica la primera deducción, pues para que se precise y se amplíe la regulación de la norma relativa a la violación de los derechos patrimoniales de autor, no se precisa de una derogación. De hecho y hasta donde es posible interpretar, pareciera que el significado del texto del parágrafo que trata sobre esta violación a través de medios electrónicos, estuviese bien orientado. Únicamente se requiere dar solución a los problemas de interpretación que surgen de su escaso abordaje, y de la indeterminación de conceptos.

Debido a la neutralidad de la tecnología que puede traer consecuencias positivas o negativas, y también a la complejidad de los conflictos originados de la relación entre nuevas tecnologías y el derecho de autor, es preciso que las generaciones actuales gocen de situaciones jurídicas reguladas por normas acordes con los escenarios generados en el marco social del uso, utilidad y aplicación de las nuevas tecnologías. 
La frontera de lo punible del derecho de autor en el entorno digital: un nuevo reto para la justicia

\section{Referencias}

Christian, D. (2012). Mapas del tiempo: Introducción a la «Gran Historia». Madrid: Grupo Planeta.

Carbajo Cascón, F. (2002). Publicaciones electrónicas y propiedad intelectual. Madrid: Colex.

Centro Colombiano de Derechos de Autor (2002). Circular Nro. 6 derechos de autor en el ámbito universitario. Recuperado el 14 de mayo de 2019 de: http://www.cecolda.org.co/index.php/derecho-de-autor/ normas-y-jurisprudencia/direccion-nacional-de-derecho-de-autor/97-circular-nro-6-derechos-de-autor-en-el-ambito-universita$\underline{\text { rio }}$

Convenio de Berna de 1886

Comunidad Andina de Naciones, Decisión 351 de 1993

Comunidad Andina de Naciones, Decisión 486 del 2000

Flórez, G. (2014).). La validez jurídica de los documentos electrónicos en Colombia a partir de sus evolución legislativa y jurisprudencial. Verba luris, (31), 43-71.

Gómez, D. (2017). Compartir no es delito. Digital Rights, 30. Recuperado el 09 de mayo de 2019 de: https://www.digitalrightslac.net/es/compartir-no-es-delito/

Hart, H. L. (1980). El concepto de derecho. México DF: Editora Nacional. L'Hoeste, F. (2016). Propiedad intelectual aproximaciones conceptuales y normatividad jurídica. Bogotá: Universidad De La Salle.

Parra, L., \& Lagunas, P. (2018). La justicia, su interpretación. Estrategias-Psicoanálisis y salud mental-, 5 .

Ríos, W. (2011). La propiedad intelectual en la era de las tecnologías. Bogotá: Universidad de Los Andes.

República de Colombia, Congreso de la República, Ley 23 de 1982

República de Colombia, Congreso de la República, Ley 1273 de 2009

República de Colombia, Congreso de la República, Ley 527 de 1999

República de Colombia, Congreso de la República, Proyecto de Ley 1462017

República de Colombia, Corte Suprema de Justicia, Sentencia del 9 de agosto de 1983 
República de Colombia, Juzgado Cuarenta y Nueve Penal del Circuito de Bogotá, Sentencia del 24 de mayo de 2017.

República de Colombia, Tribunal Superior del Distrito Judicial de Bogotá, Sentencia del 21 de noviembre de 2017.

Temperini, M. G. (2014). Delitos informáticos en Latinoamérica: un estudio de derecho comparado. XLIII Jornadas Argentinas de Informática e Investigación Operativa (43JAIIO) XIV Simposio Argentino de Informática y Derecho (SID). Buenos Aires.

Varela-Pezzano, E. (2015). Manual de propiedad intelectual. Bogotá: Grupo Editorial Ibáñez.

Vargas-Chaves, Iván (2017). Propiedad intelectual e ideas de negocio [Apuntes del Workshop]. Cartagena de Indias: Universidad Tecnológica de Bolívar.

Vargas-Chaves, I., \& Alzate-Mora, D. (2017). El derecho como un instrumento generacional y dinámico al servicio de la sociedad: un acercamiento desde la óptica Holmesiana. In Vestigium Ire, 11(1), 80-92. 
